\title{
ARQUEOLOGÍA Y PUEBLOS INDÍGENAS EN EL EXTREMO NORTE DE CHILE
}

\author{
ARCHAEOLOGY AND INDIGENOUS COMMUNITIES \\ OF NORTHERN CHILE
}

\author{
Álvaro Luis Romero Guevara*
}

\begin{abstract}
Se da cuenta del escaso desarrollo en las vinculaciones entre la arqueología científica y la población originaria en las provincias de Arica y Parinacota, extremo norte de Chile. Sólo recientemente, cuando nacen políticas estatales más efectivas de protección del patrimonio cultural y de reivindicación indígena, se han iniciado los acercamientos entre estos dos grupos sociales de la región. Se discuten las razones y soluciones para esta paradojal situación cultural en una de las regiones con mayor población originaria, gran cantidad de restos arqueológicos e investigaciones de Chile.
\end{abstract}

Palabras claves: Comunidades indígenas, historia de la arqueología, extremo norte de Chile.

In this paper I argued that there is little interaction between scientific archaeology and the indigenous population in the provinces of Arica and Parinacota in Northern Chile. Recently, with the initiation of more effective political policies toward the protection of cultural patrimony and indigenous rights, have these two social groups this begun to interact in a region with a great number of indigenous populations, archaeological investigations, and abundant cultural remains, which relationship is discussed.

Key words: Indigenous communities, history of archaeology, northern Chile.

Este ensayo da cuenta de las visiones personales de un tardío observador del desarrollo de la práctica arqueológica en las provincias de Arica y Parinacota. Desde 1995 he participado del quehacer arqueológico en el extremo norte de Chile; desde entonces he tomado conciencia no sólo a partir de las muchas publicaciones científicas regionales disponibles, de las particularidades de la práctica arqueológica de esta región. Comunicaciones personales y manuscritos mimeografiados de compañeros de trabajo con más experiencias en estos asuntos han servido además para formar las ideas aquí expresadas.

En términos generales, sigo la línea de análisis de Trigger (1992) para entender el desarrollo de la investigación arqueológica. Este autor señala que los itinerarios particulares del pensamiento arqueológico estarían basados principalmente en el contexto social donde se desenvuelven los investigadores e intelectuales. La tesis que planteo acá es que en Arica y Parinacota se ha desarrollado una fructífera labor de investigación arqueológica, con una alta especialización académica que ha logrado acumular una gran base de conocimiento.
Pese a esto último, la disciplina ha mostrado una escasa presencia en la comunidad local en términos de conocimiento específico y sobre todo en las recientemente reestructuradas comunidades indígenas.

En primer lugar reviso el contexto social y especialmente étnico del extremo norte de Chile; a continuación examino brevemente el desarrollo del pensamiento arqueológico del siglo XX; en tercer lugar repasó los incipientes encuentros entre la disciplina arqueológica y el mundo indígena de Arica y Parinacota. Para finalizar se entregan comentarios acerca del rol futuro que deben asumir las instituciones y antropólogos que trabajan el tema indígena, en conjunto con los arqueólogos para entregar las herramientas necesarias para el conocimiento y protección del patrimonio arqueológico.

\section{Población Originaria y Reivindicaciones Indígenas de los Altos de Arica}

Los primeros decenios de la llegada hispana a los Andes fueron trágicos para muchas poblacio-

* Museo Arqueológico San Miguel de Azapa, Universidad de Tarapacá, Arica, Chile. aromero@uta.cl 
nes originarias que simplemente desaparecieron. Entre ellas estaba la población costera de la subárea denominada Valles Occidentales, influenciada intermitentemente por las poblaciones altiplánicas. Estas poblaciones costeras aprovechaban un medio ambiente rico y variado, y poseían una organización sociopolítica bastante simple que implicó escasa infraestructura y monumentalidad. De este modo, si no fuera por la arqueología y la etnohistoria, estos pueblos hubieran pasado inadvertidos no sólo para la historia, sino también para sus hermanos sobrevivientes.

Los pueblos que tuvieron la suerte de sobrevivir pasaron por un largo proceso histórico caracterizado por abusos sociales, tensas imposiciones ideológicas y una constante reducción de su esfera de interacción socioeconómica. En las tierras altas de Arica se mantuvieron los herederos de una rápida colonización de la precordillera efectuada hacia el siglo X. Estas poblaciones de precordillera lograron perdurar a la llegada occidental principalmente por ocupar terrenos poco atrayentes para las personas y economías europeas. Permanecieron además largos años como sociedad debido a su compleja organización basada en una alta cohesión social e ideológica que integró los ámbitos productivos y ecológicos.

Esta subsistencia se transformó en resistencia, que se hizo patente con las revoluciones de Tupaq Amaru y los Katari, ocurridas en el siglo XVIII, en las cuales los pueblos indígenas de los Altos de Arica participaron activamente (Hidalgo y Durston 1995). Este largo proceso de desintegración y resistencia vivido de manera más o menos similar a lo largo de los Andes indígenas fue imprevistamente descontinuado en las tierras altas de Arica después de la Guerra del Pacífico (1879-1883). Con esta nueva fragmentación, tales comunidades, que ya subsistían en un medio ecológico marginal, sufrieron un dramático aislamiento de sus pares peruanos y bolivianos, de mayor densidad poblacional y enclavados en posiciones geográficas más nucleares (Albó 2000). Con esto se precipitó una rápida desestructuración sociocultural.

La constante fragmentación de la organización socioeconómica indígena es un punto recurrente que afecta gravemente su identidad. Las actuales comunidades indígenas de Chile reconocen sus tradiciones y formas económicas en las practicadas por las otras comunidades de los estados vecinos, pero no se identifican plenamente con ellas, pues ya no integran el amplio sistema sociopolítico de señoríos y cacicazgos, que funcionó y se reestructuró hasta el siglo XVIII.

A diferencia de las poblaciones originarias de Perú y Bolivia, que tempranamente se dieron a conocer como una fuerza organizada y considerada al interior de sus estados naciones, los aymaras chilenos sufrieron una fuerte chilenización o ideologización forzada de los valores patrios desde Santiago, mediante instalación de servicios públicos, educación y militarización (van Kessel 1992).

Los movimientos indigenistas de Perú y Bolivia de las décadas de 1970 y 1980 de impronta rural -y no tanto urbana- prendieron tardía y fugazmente en el norte de Chile. A mediados de la década de 1980 las juventudes urbanas letradas de origen indígena de Arica, Calama e Iquique se organizaron en movimientos reivindicativos, coincidiendo con la lucha política y social contra la dictadura militar (Gundermann 2000). Estos movimientos no sólo se basaron en las experiencias indigenistas e ideología indianista de los países vecinos, sino también en los esfuerzos paralelos de investigadores de Organismos No Gubernamentales y universidades que pusieron de relieve tales estudios.

Como producto de estos intensos esfuerzos en menos de 10 años el movimiento social indígena ayudado por el fin de la dictadura militar y la existencia de otra minoría indígena de mayor fuerza-los mapuches-, se vio favorecido en 1993 con la promulgación de la Ley Indígena $\mathrm{N}^{\circ} 19.253$ (Gundermann 2000). De esta forma, primero a través de esfuerzos de sus pares urbanos, y luego desde el poder político central, la población indígena rural superviviente se encontró ante un nuevo escenario.

Buscando recuperar un desarrollo disminuido durante siglos, la entidad gubernamental de la Comisión Nacional de Desarrollo Indígena (CONADI) instauró una serie de programas económicos, educativos y tecnológicos que otorgaron un cambio radical en la antigua discriminación negativa del ser indígena. Hoy en día ser indígena (i.e. aymara) ofrece a las personas amplias expectativas de desarrollo, a través de becas, subsidios, créditos y capacitación.

Tan contundente es la actual propuesta estatal que los recientemente indígenas se desarrollan en una amplia variedad de actividades y las comunidades indígenas rurales, que hace un decenio sufrían de despoblamiento, hoy en día poseen abul- 
tadas listas de miembros, a través del sistema andino de doble residencia. Incluso en los valles donde el sentimiento indígena nunca se registró, hoy en día está poblado por centenas de aymaras.

De este modo la actual situación étnica es una clara reconstrucción reciente o etnogénesis basada principalmente por la discriminación positiva del indígena, en donde el tema identitario pasar a ser algo más político y con fines utilitario (Gundermann 2000). Los indígenas aymaras se adscriben a un sentimiento étnico, que si bien no ha sido construido totalmente desde la nada, tampoco se basa en el reconocimiento y permanencia de formas tradicionales de organización social y económica. Es evidente que el discurso de etnicidad aymara, masivo y políticamente correcto no trasciende más allá de las costumbres, tradiciones, oralidad, lenguaje y el deber moral de ofrecer el desarrollo a las grandes masas pobres aymaras. Si existe algún vínculo con sus tradiciones remotas, tales vínculos los enlazan con las versiones mesiánicas de los indigenistas bolivianos y peruanos para interpretar las entidades prehispánicas de Tiwanaku y el Tawantinsuyu.

Con la legislación e institucionalidad de la CONADI se ha coartado todo un movimiento indigenista que a fines de 1980 promovía reivindicar los derechos sobre el agua y la tierra de los pueblos originarios, reemplazándolos por una burocracia que busca el respaldo político para ofrecer un "desarrollo con identidad".

\section{Desarrollo de las Interpretaciones Arqueológicas en el Extremo Norte de Chile}

Observamos en la reseña anterior que en el desarrollo histórico de las poblaciones indígenas e incluso en el reciente proceso identificado como etnogénesis de comunidades indígenas del extremo norte de Chile (Gundermann 2000) no se ha considerado el conocimiento que de forma científica han adquirido los arqueólogos sobre el pasado prehispánico. A continuación revisamos desde la historia de las investigaciones arqueológicas las relaciones entre los estudiosos de la prehistoria local y su contexto social.

Los inicios de la arqueología científica en Arica, con los trabajos de M. Uhle, J. Bird y G. Mostny, coinciden con la fase transicional del desarrollo de la arqueología de Chile (Núñez 1999) o quinto período (Orellana 1996). En esta fase arri- ban las posturas teóricas que estaban en boga en la antropología mundial, pero que en el esquema nacional significaron sobre todo la contraposición de diferentes metodologías para acercarse al estudio del pasado, consagrándose las excavaciones estratigráficas y los análisis regionales como las particularidades de la naciente arqueología.

Hay que pensar que la inclusión activa del norte del país como punto de investigación arqueológica no sólo se debió a la buena conservación y densidad de los restos arqueológicos, sino probablemente también para obtener una historia oficial de gran profundidad cronológica de estas tierras recientemente incorporadas al Estado chileno. Se buscaría una historia que traspasara la tenencia hispana, y sobre todo peruana y boliviana, que permitiera justificar la actual posesión chilena.

Sea cual fuere el caso, a fines de la década de 1950, el norte de Chile es centro de esfuerzos paralelos de investigadores autodidactas que entendieron que la riqueza arqueológica y etnológica debía ser difundida a nivel local y nacional (Núñez 1996). En 1957 el R. P. Le Paige creó el Museo de San Pedro de Atacama y dos años después otro grupo de investigadores autodidácticas inauguraron un Museo Regional en el centro de la ciudad de Arica. Para el caso de Arica los esfuerzos tuvieron en mente salvaguardar el patrimonio, exhibirlo a la comunidad y sobre todo estudiarlo (Álvarez 1995; Lara 1972-1973). La exposición de los hallazgos sirvió para ir conformando la extendida noción que permanece hasta hoy en día, que señala que Arica y sus valles concentran importantes yacimientos arqueológicos ${ }^{1}$.

La base interpretativa del inquieto grupo de Arica fue Percy Dauelsberg, un hombre de ascendencia germana y formado en la arqueología andina de manera autodidacta. Esta instrucción autodidacta la sustentó principalmente en su vasta experiencia de campo en Arica y sus valles, la interrelación con investigadores profesionales de Chile y Perú, y además en su experiencia de vida como comerciante en Bolivia y Arica. Esto último es quizás lo que promovió su visión altiplánica del desarrollo de las tierras bajas occidentales. Denotó mucho parentesco entre las formas de la textilería y cerámica funeraria de las poblaciones arqueológicas de Arica con las poblaciones indígenas vivas de Bolivia, usando nomenclatura aymara o quechua para muchos de los objetos arqueológicos. 
En 1967 el Museo Regional de Arica pasa a formar parte de la institucionalidad de la Universidad del Norte, gracias a esto el edificio es trasladado a las actuales dependencias de Azapa. En 1971 se crea el Departamento de Antropología, que alberga al Museo y a un grupo de investigadores con formación científica. En 1972 sale a la luz la revista Chungara, que hasta la actualidad sigue publicando las más importantes investigaciones antropológicas desarrolladas en este centro científico y la región andina general.

Este sucesivo incremento de la institucionalidad científica respondió al convulsionado ambiente sociopolítico de Chile, que desde fines de la década de 1960 hasta el abrupto fin del año 1973, buscó hacer científico y objetivo el largo recorrido humano desde el pasado prehispánico (Castro 1995). En el norte de Chile, la Universidad del Norte impulsó la creación de una carrera de arqueología fuertemente impulsada por visiones andinas integracionistas (Nuñez 1996). El naciente Departamento de Antropología de Arica pudo concentrar un cuerpo de excelencia académica con especialistas en arqueología, antropología física, antropología cultural, análisis textil, cerámico, arte rupestre y etnohistoria.

La dictadura militar tuvo desiguales consecuencias en la disciplina a lo largo de Chile: desaparecieron abruptamente carreras académicas (Concepción), en otras carreras limitaron sus promociones (Antofagasta) o disminuyeron abruptamente su planta de académicos (Santiago) (Castro 1995; Rivera 1990). Pero por diferentes circunstancias, las investigaciones arqueológicas en el extremo norte de Chile se vieron favorecidas. Primero, el flujo de especialistas que llegaron por motivos políticos desde diversos puntos del país. Tales especialidades, que originalmente se desarrollaron como disciplinas auxiliares a la antropología general, se especializaron finalmente al modo de líneas independientes de investigación, como por ejemplo, etnohistoria, tecnología textil, paleopatología, genética. Segundo, ante el influjo militar se desarrolló un segundo proceso de "chilenización" de las zonas con población originaria, la arqueología se convirtió en una disciplina necesaria para que los militares y la sociedad conservadora nacionalista pudieran disponer del conocimiento y las políticas adecuadas, sin caer en el riesgo de promover la antropología sociocultural. Tercero, la carrera de arqueología de Antofagasta pudo entregar dos generaciones de estudiantes antes que se cerrara, por tanto ese cúmulo de investigadores orientados a temas del norte chileno se desarrolló profesionalmente en las regiones de Tarapacá y Antofagasta. Cuarto, la Universidad del Norte, con sus sedes en Arica, Iquique, Antofagasta y Coquimbo, contó en los primeros años de la dictadura militar, un rector militar designado con vocación universitaria, que valoró a las ciencias antropológicas, y ofreció el marco institucional adecuado para continuar con las investigaciones (Núñez 1996).

En la década de 1980, producto del desarrollo experimentado en la década anterior, la vida académica en el extremo norte de Chile fue muy activa. Aunque también se observó un alejamiento más o menos forzado del intenso debate teórico y metodológico que se presentaba en la escuela norteamericana principalmente con la pugna de la Nueva Arqueología y las corrientes postmodernas (Trigger 1992). Esto permitió a nivel local centrarse en rellenar los vacíos históricos culturales del extenso proceso prehispánico regional de más de $10 \mathrm{mil}$ años. Junto con el aumento de la planta de arqueólogos en Arica se abrieron nuevas áreas y temas de investigación. En este período se amplía el área de trabajo -que hasta entonces incluía la tradicional excavación de cementerios de valleshacia la precordillera, el altiplano y conchales costeros.

La amplia cantidad de restos físicos humanos recolectados en décadas anteriores permitió el trabajo de científicos de las ciencias naturales, que aparte de ofrecer posturas distantes a la antropología (Nuñez 1986) permitieron a la larga la elaboración de una nueva línea de investigación: la bioantropología. El énfasis creciente en la momificación Chinchorro, fenómeno cultural que se desarrolló en lo más profundo de la secuencia (período Arcaico, entre 6.000 a 2.000 a.C.), generó amplias expectativas entre el público general, a través de medios masivos y eslóganes turísticos. Provocó además una visión externa de la disciplina arqueológica como un estudio de remotas sociedades que poco o nada tenían que ver con los pueblos originarios, de este modo la población de ascendencia indígena mantuvo cierta distancia y despreocupación del quehacer arqueológico.

Tales percepciones del público general fueron tratadas de modificar mediante distintas labores de educación y transmisión del conocimiento. Con la 
modernización de la exposición del Museo Arqueológico San Miguel de Azapa, creación de exposiciones itinerantes y la edición de libros de difusión (Hidalgo et al. 1989; Santoro y Ulloa 1985), los arqueólogos y otras disciplinas del estudio del pasado buscaron mantener su presencia en la sociedad.

En el plano teórico, se observa la incubación de un debate presente a lo largo de todos los períodos prehispánicos estudiados, centrado principalmente sobre los orígenes locales o externos de los grandes cambios culturales de esta historia. Desde el origen de la tradición cultural Chinchorro, hasta el tipo de integración regional durante el Tawantinsuyu se enfrentan estos extremos interpretativos. En cierto modo este incipiente debate puede ser considerado como el reflejo de corrientes de pensamiento mundiales frente al nuevo escenario de globalización. Este nuevo escenario mundial que enfrenta dos visiones, una que revalora lo local y propio, frente a otra que asume la globalización como un proceso permanente en la historia de la humanidad.

Por otro lado, la madurez del esquema de continuidad cultural, estructural y ecológica de los Andes a través del perfeccionamiento de la postura original de Murra (1972) permitió el debate en torno a los procesos de verticalidad y estructuralismo en la prehistoria y etnohistoria de Arica. Este tema que se inició en la década de 1970, continúa plenamente en la actualidad y puede ser entendida como la postura más cercana a una teoría antropológica general. Es desde esta perspectiva de continuidad andina que la arqueología regional va considerando a las poblaciones originarias como fuentes de información, primero en lo relativo a la ubicación y función de los sitios y objetos, y segundo en términos de interpretación cultural y simbólica del contexto arqueológico.

En la actualidad, no se han vislumbrado líneas de investigación diferentes a las que se han venido realizando en los últimos 20 años; tampoco se han observado discusiones intensas de aspectos teóricos o metodológicos, como ha sido la tónica en los años recientes de la arqueología en Chile (p.e. zona central y subárea Circumpuneña).

\section{Algunos Encuentros Entre el Mundo Indígena y la Arqueología}

Vemos que no existen relaciones permanentes entre el conocimiento arqueológico y las poblacio- nes indígenas. No es una práctica común que los investigadores entablen comunicación con las comunidades donde realizan sus investigaciones para saber su parecer ante las actividades de terreno efectuadas, ni tampoco dar a conocer directamente los resultados de sus investigaciones. Pese a esto, se han efectuado experiencias, nacidas desde el mismo marco de investigación científica, que buscan dar cabida al conocimiento vernáculo para interpretar los objetos materiales del pasado.

Ya señalamos que la fuerte noción de continuidad andina no sólo representada en los fenómenos de complementariedad, llevó a los arqueólogos a utilizar de manera anónima e indirecta el conocimiento de los actuales andinos. Tal como en San Pedro de Atacama, donde Gustavo Le Peige formó ayudantes atacameños, que hasta el día de hoy trabajan en el museo y en temas del patrimonio cultural. También en Arica se formaron colaboradores. Estos ayudantes, del tiempo de Percy Dauelsberg y Guillermo Focacci, hoy en día siguen participando casi anónimamente en las investigaciones. No sólo auxilian como mano de obra y en las instancias logísticas, sino sobre todo en el traspaso de conocimiento vernáculo en temas como toponimia, etnocategorías del medioambiente e interpretaciones culturales. Aunque este tipo de participaciones no caben dentro de la sistemática y teoría de la etnoarqueología (Kuznar 2001), no podemos negar que han ayudado e influenciado eficazmente a la investigación.

Un caso relevante y prácticamente único, es el efectuado a principios de la década de 1990, cuando surgen los movimientos indigenistas locales, donde un equipo de antropólogos culturales, especialista textil e etnohistoriadores utilizan el conocimiento vernáculo para interpretar la tecnología y sentido cultural de los textiles arqueológicos (Gavilán y Ulloa 1992).

Por otro lado, existe otro tipo de labores nacidas de las relaciones entre investigadores y autoridades que han visualizado el potencial turístico de sitios arqueológicos cercanos a poblaciones originarias. Hay que considerar que en el último decenio, con la institucionalidad de la CONADI, las autoridades locales consideran con mayor intensidad el tema indígena. En este punto es necesario repasar el caso de la puesta en valor del Tambo de Zapahuira (AZ-40).

Este sitio arqueológico había sido destruido a fines de la década de 1960 durante la construcción 
de la Carretera Internacional Arica-La Paz. Frente al daño efectuado por organismos estatales las autoridades intentaron sacar provecho a la repentina buena accesibilidad al sector arqueológico. En el año 1986 comenzaron las actividades para investigar y poner en valor el sitio arqueológico AZ-40. La iniciativa nació de investigadores del Museo Arqueológico San Miguel de Azapa, bajo el financiamiento de la Organización de Estados Americanos (OEA), quienes buscaron un nexo entre la arqueología y las iniciativas turísticas regionales (Chacama et al. 1992).

En primer lugar, se investigó con metodología arqueológica el yacimiento y el área circundante. De esta forma se pudo acceder a una compleja historia cultural prehispánica que permitió interpretar los restos arqueológicos. Hoy en día se reconoce que el sitio ubicado junto a la carretera es sólo un conjunto acotado en medio de uno de mayores dimensiones. Las estructuras más cercanas a la carretera consisten en una serie de colqas o almacenes estatales de época Inka (AZ-40 o Zapahuira 1). Mientras que las ruinas ubicadas a un kilómetro al noreste corresponden a un conjunto de RPC o kanchas con unidades arquitectónicas adosadas (AZ-124 o Zapahuira 2) (Chacama y Briones 2000; Muñoz et al. 1987).

En segundo lugar, basándose en el buen estado de conservación del complejo arqueológico, se realizaron diversas tareas de limpieza, restauración e instalación de señaléticas. Con esta puesta en valor se insertó plenamente el tema arqueológico en el floreciente circuito turístico del Parque Nacional Lauca. Pero las ruinas también sufrieron evidentes efectos negativos. La suciedad, el deterioro de la señalética y diferentes tipos de alteración de los restos arqueológicos llamaron la atención del Consejo de Monumentos Nacionales, al Museo Arqueológico y finalmente a CONADI.

En este punto CONADI retoma el tema de patrimonio arqueológico y cultural desde el punto de vista del desarrollo de las comunidades indígenas rurales. Los temas etnoturísticos fueron visualizados por las autoridades locales de la Subdirección Norte de la CONADI como un excelente motivo para integrar y fortalecer el desarrollo del mundo indígena rural. En conjunto con especialistas de la Universidad de Tarapacá se elaboraron catastros del patrimonio arqueológico del extremo norte de Chile y una primera aproximación a la difusión de los temas del patrimonio cultural indígena (Espinosa et al. 1998). Lamentablemente tales iniciativas derivaron prontamente en visiones netamente desarrollistas. En la actualidad, ni las autoridades y menos la población de base indígena están interiorizados del específico marco legal que regula el patrimonio indígena, de la conservación, interpretación e investigación de los sitios arqueológicos; por lo tanto no disponen de una clara visión de la situación de su patrimonio arqueológico.

Las autoridades de la Subdirección Norte de la CONADI, herederas del proceso de movilización étnica de la década de 1980 y principios de 1990, legitimado sobre fuentes muy generales acerca de la historia y prehistoria de las sociedades andinas, han desestimado una vinculación más cercana con las fuentes del conocimiento especializado, es decir, los centros de producción científica. Es lógico que como organismo público destinado al desarrollo, no se vinculen con el quehacer científico especializado, pero es su deber trabajar con los profesionales necesarios para conformar el segundo objetivo de su misión: la identidad.

Para ese objetivo se hace necesario trabajar tanto con la difusión de conocimientos especializados en temas antropológicos e históricos, como en los aspectos organizativos y educacionales y no solamente en torno al desarrollo.

En este contexto la Oficina Arica de CONADI en la Subdirección Arica ha propiciado, a continuación del catastro y evaluación del patrimonio arqueológico indígena, la búsqueda de nuevas alternativas etnoturísticas. Se encargaron los estudios para una nueva puesta en valor de Zapahuira 1 que consideró circuitos turísticos de mayor envergadura con relativa participación de las comunidades indígenas y sobre todo con agentes turísticos. En estos estudios de preinversión la interpretación cultural fue entendida como la difusión de los resultados de las investigaciones arqueológicas a agentes turísticos. Además, la administración del recurso cultural debería estar a cargo de entidades que respetaran la legalidad y la sustentabilidad del recurso y no debían ser necesariamente de origen indígena (Chacama y Briones 2000).

En este marco de accionar de CONADI, y ante una sensibilización nacional en los temas de patrimonio derivados de las políticas culturales de los gobiernos de la Concertación Democrática se efectuaron algunas acciones nacidas en el interior de las mismas comunidades indígenas. Como era de esperar, por el desconocimiento general de las mí- 
nimas normas de manejo y de conservación de los restos arqueológicos, y ante la inexistencia de instancias de diálogo con los especialistas, algunos de estos empeños por fortalecer el "desarrollo con identidad" provocaron graves daños al patrimonio.

En este caso una pequeña comunidad indígena de miembros con doble residencia urbanorural, se adjudicaron un proyecto del Fondo de Arte y Cultura del Ministerio de Educación $(\text { FONDART })^{2}$. El proyecto contemplaba la restauración y habilitación turística de las ruinas arqueológicas ubicadas a $5 \mathrm{~km}$ hacia el oeste del pueblo de Chapiquiña, provincia de Parinacota. Ante esa instancia ningún organismo, como el Ministerio de Educación o el Consejo de Monumentos Nacionales, se percataron de la irregularidad. Es así que durante el primer mes de ejecución, se alteró fuertemente cerca de un $20 \%$ del área arqueológica, recogiendo materiales arqueológicos y removiendo contextos funerarios.

Comunicados el Consejo de Monumentos Nacionales y FONDART de esta situación, se logró reorientar parte de los fondos del proyecto hacia la investigación (Romero 2002). Como iniciativa aislada esta experiencia no permitió el traspaso efectivo de los temas patrimoniales a las bases indígenas y tampoco a las autoridades respectivas de CONADI.

\section{Discusión y Comentarios Finales}

Recapitulando las reseñas anteriores observamos tres tipos de actitudes en torno a las poblaciones originarias, su historia y patrimonio arqueológico. Primero, desde la implantación de una política oficial chilena hasta 1993, los pueblos indígenas son observados como grupos que deben ser incorporados de una u otra forma a la sociedad mayor, por tanto su historia específica no es relevante, pues en algún momento se sumarán a la historia oficial. Pese a esto, la arqueología entre 1920 y 1960 tuvo como labor descartar tal interpretación, confiriendo una mayor antigüedad y especificidad que la relatada por la historia ${ }^{3}$.

Segundo, una visión desde los movimientos reivindicativos locales, que nacen en relaciones políticas y sociales con grupos peruanos y bolivianos, y que se instituyen en el plano regional en el fervor de las protestas hacia la dictadura militar. Dicho movimiento cesó radicalmente con la nueva legislación indígena de 1993, y sólo permanece de forma no estructurada en pensamientos y posturas románticas. En dichos casos, el uso del conocimiento y la expresión del pasado consideran sólo la historia y la etnohistoria ${ }^{4}$ de las grandes entidades integradoras prehispánicas de Tiwanaku y Tawantinsuyu.

Tercero, la reciente institucionalidad de CONADI que busca "desarrollo con identidad", está formada por el mismo grupo dirigente de los movimientos reivindicativos de décadas anteriores, en un nuevo escenario político que busca legitimar su accionar frente a adversarios políticos y unificar la dispersa base indígena. No utilizan el conocimiento específico del pasado y patrimonio de las comunidades indígenas, ya que siguen utilizando versiones mesiánicas de los grandes estados prehispánicos, y sobre todo una serie de aspectos generales de la etnografía aymara para integrar a los diversos actores rurales y urbanos, tales como la oralidad, las costumbres, las festividades y la lengua. La identidad que se busca reforzar, al parecer, es de tipo instrumental y no se basaría en el sentir y saber de las comunidades de base.

Por otro lado, la investigación arqueológica tampoco ha considerado a los pueblos indígenas ni como receptoras de su conocimiento ni menos como fuentes de investigación, a las cuales puedan incorporarse sistemáticamente, por medio probablemente de la etnoarqueología. El actual contexto de investigación científica nacional ha financiado la investigación en ciencias sociales propiciando en arqueología la especialización y su adscripción a marcos teóricos generales. Pero este desarrollo ha sido en desmedro de las particularidades de las ciencias sociales y sus diferencias con las ciencias exactas y naturales.

Así como las ciencias duras tienen su contraparte en la tecnología o ciencia aplicada, las ciencias sociales deberían tener su contraparte en la difusión, educación y política. Para la arqueología eso es fundamental ya que no sólo investigamos en gran medida con recursos fiscales, sino que además legalmente trabajamos con el patrimonio cultural de todos los ciudadanos. La sociedad no nos pide aplicaciones prácticas como puede solicitar abiertamente a las ciencias "duras"; la sociedad solicita información con la cual implementa la educación y políticas sociales.

Debemos comentar finalmente el tipo de relación que tienen las bases de los pueblos originarios respecto a su propio patrimonio. Podemos afir- 
mar que de una u otra forma la población de raíz indígena ha mantenido siempre una relación con el patrimonio arqueológico que ha heredado. Los reconocen como "gentiles", con toda una mitología bien definida y compartida. Pero los múltiples procesos políticos, económicos y demográficos a que han sido sometidas las poblaciones de los altos de Arica han provocado un distanciamiento: los "gentiles" no son ni achachis ni abuelos, son los de otro tiempo que les heredaron un paisaje y no una cultura. Mucho más integrados a las comunidades se encuentran las cruces de mayo, las antiguas iglesias, las huellas troperas y las terrazas de cultivo abandonadas.

Ante este escenario, el patrimonio arqueológico no es asumido como un patrimonio hasta que no se les ve con ojos desarrollistas, como el que ha generalizado la institución de la CONADI, con su discriminación positiva de los indígenas y su mundo. Así de tajante se puede afirmar que si no hay una idea de provecho económico no nace una ligazón entre comunidades y restos arqueológicos.

La discusión en la agenda indígena acerca de su patrimonio arqueológico sin un amplio marco de conocimiento, puede conllevar a diferentes tipos de conflicto no sólo en cuanto a la conservación del patrimonio arqueológico, sino también al interior de las mismas comunidades indígenas. Un primer conflicto es el de legitimidad. No hay duda de que los pueblos de raíz indígena son, en general, los herederos legítimos del patrimonio prehispánico. Pero si no existe una efectiva identidad solidaria entre las comunidades, arraigada en el conocimiento del pasado y su patrimonio, no se podrán solucionar futuros conflictos sobre el derecho de explotación económica de un mismo bien patrimonial entre diferentes comunidades o asociaciones indígenas.

Otro conflicto tiene que ver con las estrategias de desarrollo turístico. A diferencia de la provincia de El Loa, donde se sitúa el importante centro turístico de San Pedro de Atacama, las tierras altas de Arica y Parinacota poseen una limitada demanda turística. Propiciar el etnoturismo incorporando a las empresas urbanas, que poseen el capital y una relativa experiencia para enfrentar esta escasa demanda, significa postergar a la masa indígena. Si no se incentiva la identidad, las organizaciones y la identidad indígena antes de este proceso de comercialización de la oferta etnoturística se provocará algo similar a lo que ocurre hoy en día en San Pedro de Atacama, donde una gran masa indígena no participa de la rentable actividad turística.

Para finalizar, se debe recalcar que tradicionalmente la investigación arqueológica del extremo norte de Chile no ha podido trascender las imposiciones del sistema científico nacional. Esto no es de exclusiva responsabilidad del aparato burocrático de las ciencias, que no privilegia la difusión y la interacción con las poblaciones herederas directas del patrimonio arqueológico, sino también de la falta de conexión social de los investigadores.

Los arqueólogos hemos debido trabajar de acuerdo a los diferentes marcos sociales en los cuales nos desenvolvemos, en donde el tema indígena, pese a ser uno de los focos principales de nuestra investigación no había sido entendidos o situados como actuales sujetos sociales. Pero dentro del mismo escenario político se pudo desarrollar desde el inicio de la década de 1980 una línea de trabajo diferente en las tierras altas de la Región de Antofagasta (Aldunate et al. en este volumen), y que ya posee una segunda generación de profesionales (Ayala et al. en este volumen; Carrasco et al. en este volumen; Uribe y Adán en este volumen).

Más que errores garrafales o aplicaciones inocentes del método científico, lo que ha primado en el modo de hacer arqueología en el extremo norte de Chile ha sido principalmente una falta de sensibilidad social frente a los distintos escenarios culturales que se han desarrollado en estos últimos cien años. Como profesionales del patrimonio arqueológico, ayudados por las actuales sensibilidades sobre el patrimonio nacional tenemos hoy en día la responsabilidad de difundir e integrar nuestro conocimiento y experiencia a todos los sectores de la sociedad. Para eso debemos propiciar el desenvolvimiento de los arqueólogos y el tema del patrimonio cultural en los diversos campos a nuestra disposición.

Agradecimientos: A los organizadores del Encuentro de Ollaguie: Patricia, Sergio y Ulises; a la comunidad que nos recibió y al extenso grupo de colegas, comuneros y dirigentes que dialogaron y debatieron con nosotros. También a los colegas de Arica que me entregaron sus ideas, experiencias y 
propuestas inéditas en relación a los temas tratados: Juan, Lucho, Calogero y Gustavo. Es la ocasión para homenajear a Andrés Vilca, que junto a otros hombres andinos han ayudado a diferentes investigadores del Departamento de Arqueología y Antropología de la Universidad de Tarapacá en la parte logística e interpretativa. Sin duda, Andrés y los demás han seguido una vocación interna, y no meramente laboral, que los ha motivado a participar en la reconstrucción de la historia de nuestros antepasados. Este trabajo es resultado del proyecto FONDECYT 1000457.

\section{Referencias Citadas}

Albó, X.

2000 Aymaras entre Bolivia, Perú y Chile. Estudios Atacameños 19:43-74.

Álvarez, L., editor

1995 Museo Regional de Arica. Reedición Boletines del 1 al 7. Octubre de 1959 - Febrero del 1961. Universidad de Tarapacá, Arica

Castro, V., editora

1995 Mesa de la generación de los '70. Boletín Sociedad Chilena de Arqueología Número Especial: 13-27.

Chacama, J., L. Briones e I. Muñoz

1992 Puesta en valor de un sitio monumental prehispánico Tambo Zapahuira 1 (AZ 40). Hombre y Desierto 7-8:23-37.

Chacama, J. y L. Briones

2000 Puesta en valor Tambo de Zapahuira. Informe preparado por Consultora GAIA Limitada para CONADI, Arica. Manuscrito en posesión de los autores.

Espinosa, G., W. Quispe, C. Santoro, H. González y J. Córdova 1998 Participación de la Comunidad Aymara en la conservación y manejo del patrimonio arqueológico de las provincias de Arica y Parinacota. En Patrimonio Arqueológico Indígena en Chile. Reflexiones y Propuestas de Gestión, compilado por X. Navarro, pp. 113-131. Universidad de La Frontera y UNESCO, Temuco.

Gavilán, V. y L. Ulloa

1992 Proposiciones metodológicas para el estudio de los textiles andinos. Revista Andina 19:107-134.

Gundermann, $\mathrm{H}$.

2000 Las organizaciones étnicas y el discurso de la identidad en el norte de Chile, 1980-2000. Estudios Atacameños 19:75-91.

Hidalgo, J. y A. Durston

1998 Reconstitución étnica colonial en la sierra de Arica: El Cacicazgo de Codpa 1650-1780. En Actas del IV Congreso Internacional de Etnohistoria, Vol. 2: 32-75. Pontificia Universidad Católica del Perú, Lima.

Hidalgo, J., V. Schiappacasse, H. Niemeyer, C. Aldunate e I.

Solimano, editores

1989 Culturas de Chile. Prehistoria. Editorial Andrés Be1lo, Santiago.

Kuznar, L., editor

2001 Ethnoarchaeology of Andean South America. Contributions to Archaeological Method and Theory. Ethnoarchaeological Series 4, International Monographs. En Prehistory, Ann Arbor.
Lara, R.

1972-1973 Un año más del Museo Arqueológico San Miguel de Azapa. Chungara 1-2:7-9.

Muñoz, I., J. Chacama, G. Espinosa y L. Briones

1987 La ocupación prehispánica tardía de Zapahuira y su vinculación a la organización económica y social Inca. Chungara 18:67-89.

Murra, J.

1972 El control vertical de un máximo de pisos ecológicos en la economía de las sociedades andinas. En Visita de la Provincia de León de Huanuco en 1562, editado por J. Murra, pp. 427-476. Universidad Nacional Hermilio Valdizán, Huanuco, Perú.

Núñez, L.

1986 El patrimonio arqueológico chileno: Reflexiones sobre el futuro del pasado. Discurso de Incorporación al Instituto de Chile. Academia Chilena de Ciencias Sociales, Santiago.

1996 La Universidad Católica del Norte y su misión antropológica en el desierto chileno. En La Universidad Católica del Norte y el Desarrollo Regional Nortino, editado por J. González, pp. 209-245. Ediciones Universitarias, Antofagasta.

1999 Chile. En Encyclopedia of Archaeology. History and Discoveries, editado por T. Murray, Vol. I: 301-315. ABC Clio, Santa Bárbara, California.

Orellana, $\mathrm{M}$.

1996 Historia de la Arqueología en Chile. Bravo y Allende Editores, Santiago.

Rivera, M.

1990 La investigación arqueológica en el norte de Chile, 1984-1990. Evaluación y perspectivas. Revista Andina 16: 555-578.

Romero, Á.

2002 El pukara de Caillama, las chulpas de barro y el control político de la sierra de Arica en el período Intermedio Tardío. Boletín-e AZETA (febrero) http://www.uta.cl/ masma/azeta/caillama (marzo 2002)

Santoro, C. y L. Ulloa, editores

1985 Culturas de Arica. Serie Patrimonio Cultural Chileno, Ministerio de Educación, Santiago.

Trigger, B.

1992 [1989] Historia del Pensamiento Arqueológico. Editorial Crítica, Barcelona.

Van Kessel, J.

1992 Holocausto al Progreso. Los Aymaras de Tarapacá. Editorial Hisbol, La Paz. 


\section{Notas}

1 Noción que puede ser también contraproducente. En pleno siglo XXI, funcionarios gubernamentales de la región, ante la noción que la cantidad de sitios conocidos e investigados es suficiente, sugieren detener la acumulación de objetos arqueológicos y momias para acelerar el desarrollo social.

2 Proyecto FONDART 49716 "Restauración de Ruinas Indígenas en Alto Chulpane" adjudicado por la Comunidad Indígena de Chapiquiña en el concurso 2000.

3 Un caso paradigmático es el del R. P. Gustavo Le Paige, que no sólo mostró una antigua cultura prehispánica en la cuenca de San Pedro, sino que le dio una continuidad cultural que sirvió para identificar una población etnográfica, no sólo ante la sociedad general, sino sobre todo a los mismos locales que desde entonces ostentaron una identidad como atacameños (Núñez 1996). Podemos afirmar que este caso es el único ejemplo de quehacer arqueológico en el norte de Chile que influyó en las poblaciones indígenas.

4 Estos movimientos casi nunca consideraron la arqueología, debido a la especialización de sus conocimiento y lenguaje y porque escasamente interpreta los procesos históricos. 